\title{
CT Aided Postoperative Breast Conservation Brachytherapy Irradiation
}

\author{
D. O. Odero \\ Department of Physics and Astronomy, University of Ohio, Athens, Ohio \\ Radiation Oncology, Raleigh Regional Cancer Center, Beckley, West Virginia \\ USA
}

\section{Introduction}

Breast cancer, with its uncertain causes and confusion over the best treatments, has intrigued the scientific community for years. Numerous resources have been and continue to be devoted to research and technical developments to understand its causes, prevention and treatment. Despite this, breast cancer still remains the most common malignancy and dreaded disease in women in the United States (American Cancer Society [ACS], 2003). Progress has been made, nevertheless, in humanizing the horrors that formerly devastated the body and psyche (Andersen et al., 2008).

Anatomically, breasts are hemispherical in shape and are made up of glandular tissues embedded in connective tissue which lie over the pectoral muscles. Adipose tissues lie between the skin and the glandular tissues, and the size of breasts depend on the adipose tissues. As a woman ages, the adipose tissues of the breasts may become more prominent than the glandular tissues, and the breasts may become softer and begin to be flaccid. Breast cancer is more prevalent in elderly women as they age. The challenges that come with age and the aforementioned breast structure complicates the treatment of breast cancer particularly with radiation.

The most common site of breast cancer is the upper outer quadrant followed by the central area.

Curative treatment of breast cancer include combined modality treatment, which incorporates surgery (radical or conservative) and adjuvant treatments such as chemotherapy, hormonal therapy, external beam irradiation and brachytherapy implantation. The selection of a particular procedure or a combination of procedures depends on established prognostic factors such as stage, grade and extension. In general, surgery is indicative if the tumor is confined to the breast with no extension through the lymphatic system. Brachytherapy implants are used for early stage cancers, either alone or in conjunction with external beam radiation therapy. Patients who require breast conservation using surgical procedures are often potential candidates for brachytherapy as well (Calle et al., 1978; Fisher et al., 1977; Harris et al., 1981; Levene, 1977; Pierquin et al., 1980; Prosnitz et al., 1977); however, patients with extensive tumors are not good candidates for brachytherapy implantation.

Many women with early-stage breast cancer are treated with breast-conserving surgery (lumpectomy) followed by external-beam radiation. The typical radiation course is 
delivered five days a week for six to seven weeks. A standard "boost" or increased dose to the lumpectomy site usually takes an additional one and one-half to two weeks after the whole breast is treated with a standard radiation regimen. For the external beam radiation treatment to be effective, the geometric location of the affected breast needs to be reproducible (Byhart et al., 1978). Unfortunately, flaccid breasts and the proximity to critical healthy organs such as heart and lungs present a great technical challenge even with superior immobilization tools (Van Arsdale \& Greenlaw, 1971). Postoperative intracavitary brachytherapy, delivered twice a day for five days circumvent the technical problems experienced with external beam irradiation. This type of treatment is recommendable for patients with large breast and/or deep-seated tumors although the available data is not yet enough for analysis to conclusively predict the long term outcomes.

Volumetric imaging technology with fast automated visualization and geometric measurement tools has greatly influenced the current practice of breast brachytherapy. Precise details of the tumor or tumor bed help to delineate the area to be treated and to determine the necessary margins around the tumor in breast cancer as well as in other malignancies (Ricke et al., 2004; Manning, 2001).

Details of the clinical aspects of breast cancer and its treatment are beyond the scope of this chapter. This chapter discusses the physical and technologic aspects of the CT aided breast implants using high dose rate (HDR) Iridium-192 afterloading techniques.

\section{Breast cancer diagnosis and tumor localization}

Mammography remains the major and most reliable imaging method used in breast mass detection. On a mammogram, breast cancer typically appears as an ill-defined, opacified lesion with or without speculated margins (see Figure 1). It can detect small, discrete lesions and chest wall involvement. Unfortunately, mammography presents some challenges such as discomforts when the breast is compressed between positioning paddle and image receptor (see Figure 2), potential image artifacts associated with different breast structures overlying each other rendering the tumor difficult to discern, non-differentiation between tumor and malignancy, and limitation to only two-dimensional (2D) interpretation of images.

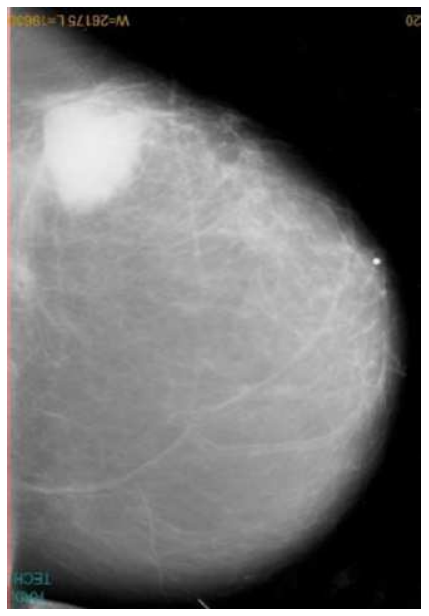

Fig. 1. Mammogram showing an ill-defined opacified breast lesion 


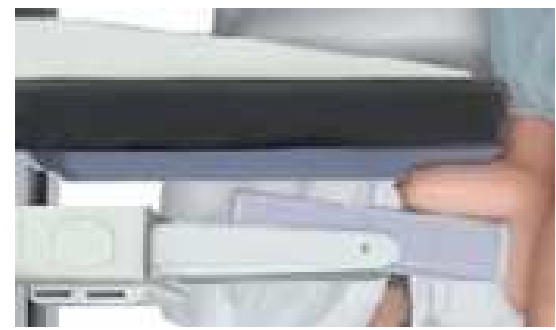

Fig. 2. Mammography - breast compressed on image receptor

CT imaging presents a better three-dimensional (3D) understanding of pathological lesions when they are present, eliminates the compression and can distinguish between the image artifacts and true abnormalities. It is an important tool for the evaluation of local and regional disease in selected patients who have an established diagnosis of breast cancer. However, CT scanners use x-rays at higher energies than do mammograms, reducing the contrast of the images and the ability to distinguish the calcification. For this reason, a CT scanner is less efficient than regular mammography at detecting the tiny clusters of calcium (or microcalcifications) that can sometimes be indicative of breast cancer (Zwicker et al., 1985). CT scanners also have an extra disadvantage of emitting unnecessary radiation exposure to the non-targeted parts of the patient.

A definitive diagnosis of breast cancer can only be made through a microscopic examination of breast tissue obtained from a biopsy. As has been aforementioned, breast cancer is currently the most common malignancy in women; consequently, development of robust screening and detection techniques that can provide earliest diagnosis is necessary since that can lead to cure (Henderson, 1980; Schottenfeld et al., 1976). Such systems should be accurate, cost effective, and non-invasive and should present three-dimensional visualization of the diseased area. A prototype dedicated breast CT has recently been presented (Lindfors et al., 2008).

\section{Postoperative breast brachytherapy irradiation}

Postoperative irradiation of the breast following a breast-conserving surgical procedure to remove gross tumor is an example of combined surgical and radiation therapy management of local disease. Surgery removes gross tumor while irradiation eradicates subclinical disease in the tumor bed (Calle et al. 1986; Fisher, 1986) to reduce local recurrence (Holland et al., 1985).

The disadvantages of external beam irradiation include the time required for protracted course of treatment, which can last up to seven weeks, as well as radiation exposure to the heart, lung, and normal breast tissue. The development of high activity artificial isotopes (International Atomic Energy Agency [IAEA], 1967; Nath, 1983; Trott 1988), afterloading techniques (Almond, 1983; Delcos, 1980; Delcos, 1992; Glasgow,1995; Henschke et al., 1963; Hillaris, 1975; Pain, 1972; Syed \& Feber 1977; Syed et al., 1977 ), and automated devices with remote control has stimulated renewed interest in brachytherapy.

Brachytherapy can be performed using external surface molds, intracavitary, interstitial, or intraluminal techniques or a combination of these methods. Brachytherapy allows delivery of high dose radiation to the tumor while minimizing radiation exposure to normal tissues by eliminating the unavoidable transit irradiation occurring with external irradiation, and by allowing a highly conformal dose delivery. The radioactive materials used in 
brachytherapy are of high activity. To allow normal tissue sublethal damage repair, high dose rate brachytherapy is generally fractionated. Before each fraction, images are obtained to determine the geometry of the radioactive sources and their relationship to anatomic targets.

\section{Three-dimensional brachytherapy treatment-planning system}

Treatment planning is often characterized by the dimensionality of the calculation algorithm. Two-dimensional algorithms have limited anatomy considerations with limited evaluation tools, and in some cases are single point calculations. Three-dimensional algorithms depend upon CT-acquired 3D data sets with comprehensive anatomy, can model 3D dose corrections and use volumetric evaluation tools. 2D calculations represent the dose seen in a single cross sectional slice in an ellipsoid of infinite length and of uniform electron density, while 3D algorithms model the dose obtained in actual patient CT data sets. 3D treatment planning in brachytherapy is therefore the process by which 3D visualization, dose calculation, and plan evaluation tools are used to optimize treatment. Tumor size and shape, as well as outlines of anatomic structures, are adequately established by the use of CT. Tumors of unusual shape or that are located adjacent to radiosensitive tissues benefit from CT based computerized treatment planning.

The development of 3D brachytherapy treatment planning tools has lagged behind that of external beam planning tools. Target definition has traditionally been applicator oriented. Technical developments in brachytherapy treatment planning have been mainly oriented towards conventional $x$-ray films and very little towards volumetric sectional imaging. The present movement towards 3D image based brachytherapy has been influenced less by the procedure itself and largely by the advancements in the 3D imaging equipment and computer technology that offers the physicians and the planning team the flexibility of understanding the physical aspects of the treatment. McGee and McShan (McGee \& McShan, 1988) claimed that the breast brachytherapy based on sectional imaging provides a major contribution to brachytherapy procedure giving examples of potential impacts based on their clinical experience. This experience did not include 3D assessment of anatomy, target, critical organs and 3D image based 3D dose calculations with corresponding display and evaluation capabilities according to ICRU report, 50 (ICRU, 1983). Presently, there has not been similar frame to what ICRU put down in the report 50 (ICRU, 1983) for breast brachytherapy. Calculations based on 2D algorithms ignore the inhomogeneities associated with different composition of human tissue, but with appropriate electron density conversions, CT data can be used to perform bulk dose inhomogeneity corrections in 3D planning (Almond, 1983).

The optimal radioactive source dwell locations and dwell durations can be calculated with the aid of a treatment planning computer based on the prescribed dose. The treatment planning software can optimize these variables once the tumor volume and normal tissues and their dose constraints have been delineated by the radiation oncologist.

3D planning software uses sophisticated Sievert integral algorithms that break a linear radioactive source into tiny components, calculates the dose at every point in the patient from every component, and sums these values to get the final result (Edmundson, 1994). In keeping with the principles used in 3D external beam radiation planning, breast brachytherapy planning begins by delineating the applicator, air pockets and seroma, and other critical normal organs such as chest wall, heart, lungs, and skin. Planning treatment 
volume (PTV) in breast brachytherapy using inflatable balloon applicators requires coverage of $1 \mathrm{~cm}$ to $2 \mathrm{~cm}$ from the applicator which can be constructed using a uniform ring around the applicator.

\section{Quality assurance for 3D computer treatment planning system and CT}

It is valuable to scan a simple geometric phantom and send this data through the planning process on a weekly or monthly basis. A known phantom geometry should be aligned using lasers, scanned, and the images transferred to the computer planning system. Simple measuring tools in the planning system can serve as a quick check for geometric distortions, image scale, and orientation.

\section{CT based accelerated partial breast irradiation}

To demonstrate the benefits of the CT image based 3D treatment planning and breast brachytherapy, a MammoSite RTS single channel spherical balloon applicator (Cytyc Corporation, Hologic LP, Marlborough, MA 07152 USA) with Varian Brachyvision 3D treatment planning system together with Varian GammaMed Plus ix (Varian Medical Systems, Inc, Charlottesville, VA 22903) high dose rate (HDR) afterloader is illustrated.

\subsection{Intraoperative applicator insertion}

MammoSite radiation therapy is a form of accelerated partial breast irradiation (APBI), where an afterloading balloon applicator (Figure 3) is inserted directly onto the lumpectomy cavity (MammoSite, 2010).

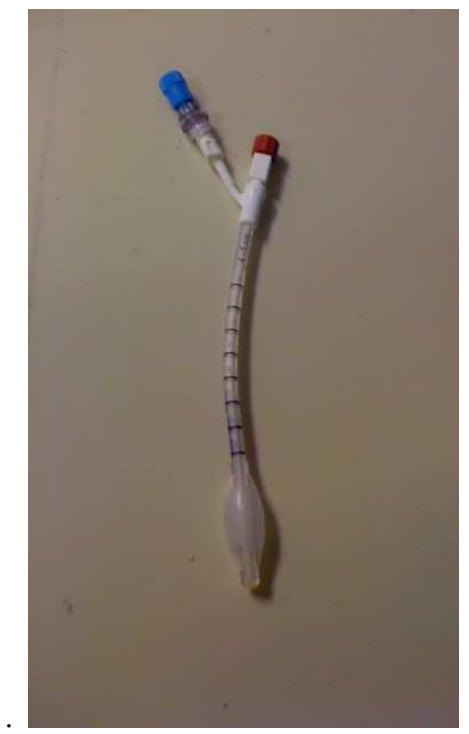

Fig. 3. Deflated MammoSite balloon applicator

Blue -Fluid port for balloon water mixture inflation

Red - Source port for radioation source wire connector 


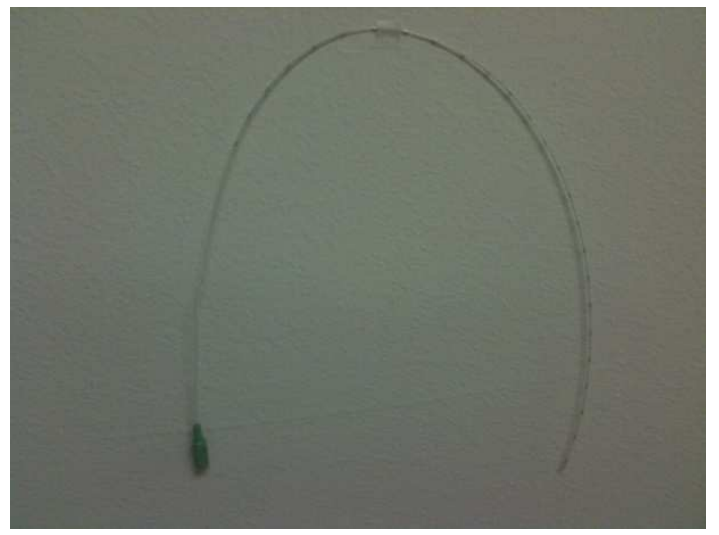

Fig. 4. Dummy source wire with dummy sources

MammoSite RTS is suitable for ductal carcinoma in situ, as well as invasive carcinoma (Besaleh et al., 2009). The location of the tumor and post-surgical seroma determine whether a patient is a candidate for this treatment. The balloon must be at least 5 to $7 \mathrm{~mm}$ away from the skin, so the technique may not be suitable for small breasted women, or for tumors found near the edge of the skin. The lumpectomy cavity must be spherical, or nearly so, in order for the balloon to conform to the seroma without air pockets. The cavity must also be large enough to allow a balloon volume of at least $30 \mathrm{cc}$. The balloon is inflated with a dilute mixture of iodinated contrast media to allow CT evaluation of balloon position (Souba et al., 2007).

The MammoSite placement procedure begins by performing the lumpectomy and surgically preparing the cavity for MammoSite balloon applicator. The applicator can then be implanted at the time of the lumpectomy or post lumpectomy.

\subsection{Breast brachytherapy treatment planning CT images}

Patient data acquisition is an important part of the treatment simulation process, since reliable data is required for computerized treatment planning purposes and allows for a treatment plan to be properly carried out.

The patient should be scanned in supine position with hand over the head unless the chest wall is involved or is less than $7 \mathrm{~mm}$ to the balloon surface. Ideally, the treatment CT scanning should be performed 48 hours after the balloon insertion.

Transverse CT scans contain all information required for complex treatment planning in radiation therapy treatment.

Breast CT scan, with radiographic markers (see figure 4 with dummy sources) in place, is required to verify the patient's appropriateness for treatment with brachytherapy and to proceed with 3D planning. A slice width of $3 \mathrm{~mm}$ is recommended for adequate resolution of the applicator and surrounding breast tissue on the acquired axial images as well as coronal and sagittal reconstructions. Pilot or scout films relate CT slice position to anteriorposterior and lateral radiographic views of the patient at the time of scanning. They are obtained by keeping the $\mathrm{x}$-ray source at a fixed position and moving the patient (translational motion) through the stationary slit beam. The result is a high definition radiograph which diverges on the transverse axis, but does not diverge on the longitudinal axis (see Figure 5). The patient image data is then transmitted to the treatment planning 
computer via either network or portable media using DICOM 2 format or DICOM RT format (ICRU, 1999). It is advisable to archive these images as secondary backup should the treatment planning computer images be corrupted or be unusable. The conformance of the cavity to applicator surface, distance from the balloon applicator surface to skin, and the diameter and symmetry of the applicator then needs to be evaluated either at the CT computer or at the treatment planning computer to determine if the treatment can be delivered. Ideally, this process should be performed while the patient is still on the CT table so that if it is necessary to adjust the balloon volume, this can still be easily done with a follow up CT to confirm the change.

The minimum balloon's surface to chest wall/ ribs distance should also be checked to be not less than $7 \mathrm{~mm}$. If it is less than $7 \mathrm{~mm}$, then the patient should be rescanned and treated in prone position with the aid of customized breast board immobilizer.

Figures 6 through 8 and tables 1 through 5 illustrate these parameters for MammoSite RTS applicator.

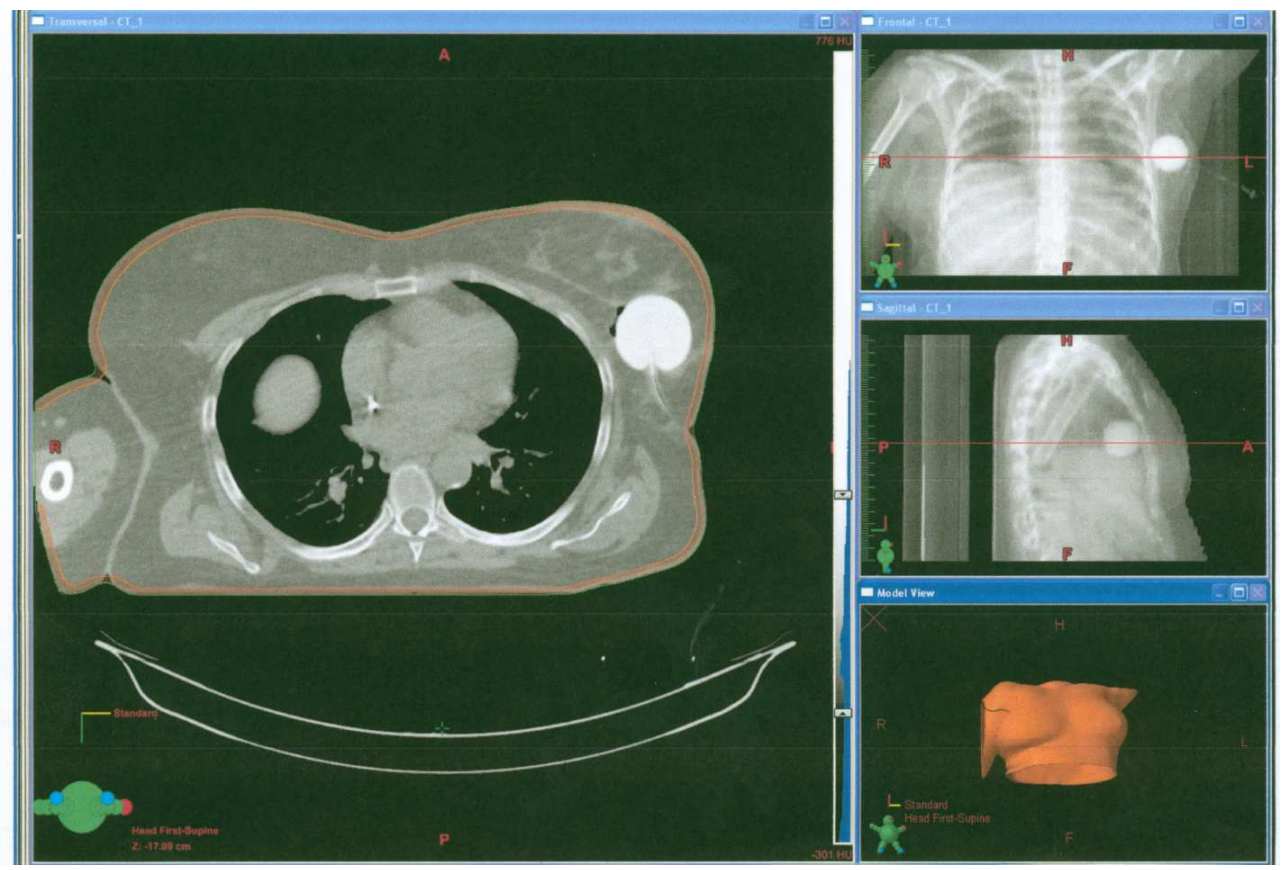

Fig. 5. Breast topogram

\begin{tabular}{|l|c|c|}
\hline Orientation & Measured, $\mathrm{x}(\mathrm{mm})$ & $\mathrm{x}$ within or greater than $(5 \mathrm{~mm}-7 \mathrm{~mm}) ?$ Pass/Fail \\
\hline Transverse & 11.8 & Pass \\
\hline Frontal & 9.7 & Pass \\
\hline
\end{tabular}

Table 1. Minimum balloon's surface to skin distance after consideration of all the CT slices. The measurements are a pass if they are within or greater than $5 \mathrm{~mm}-7 \mathrm{~mm}$ and a Fail otherwise. 


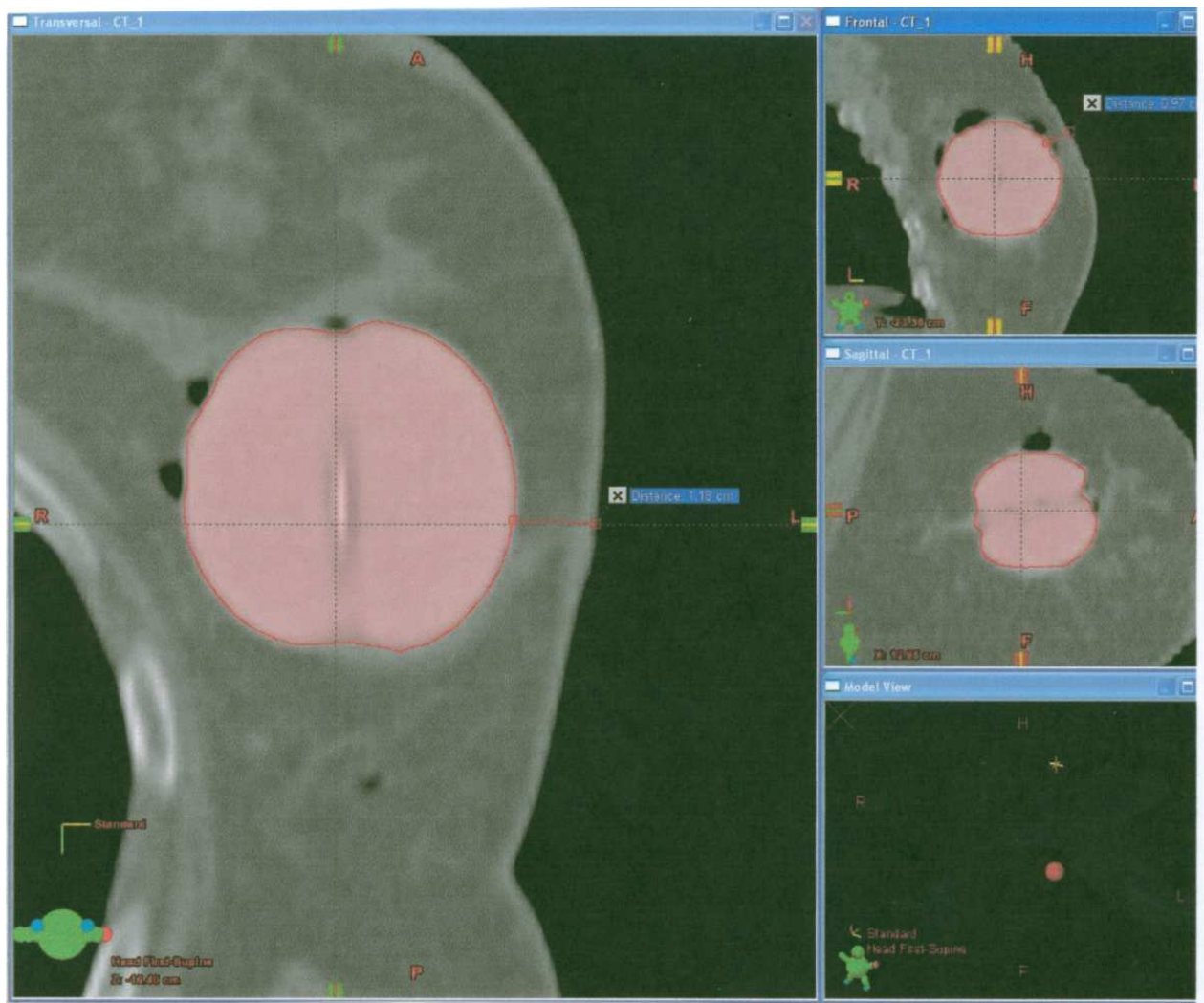

Fig. 6. This figure shows the measured distances from the balloon's surface to the skin in three different orientations. Shown are the CT slices with the shortest distances. Frontal view shows the shortest distance of $9.7 \mathrm{~mm}$ which is beyond the acceptable minimum distance of $5 \mathrm{~mm}$.

\begin{tabular}{|l|c|c|c|}
\hline Orientation & Diameter, $\mathrm{d} 1 \mathrm{~cm}$ & Diameter, $\mathrm{d} 2 \mathrm{~cm}$ & $\begin{array}{c}4.0 \leq \mathrm{d} \leq 5.0 \mathrm{~cm} \\
\text { Pass } / \text { Fail }\end{array}$ \\
\hline Transverse & 4.76 & 4.73 & Pass \\
\hline Frontal & 4.18 & 4.55 & Pass \\
\hline
\end{tabular}

Table 2. Inflated 4.0 - $5.0 \mathrm{~cm}$ MammoSite RTS. The transverse diameter, $\mathrm{d} \mathrm{cm}$ should range between $4 \mathrm{~cm}$ to $5 \mathrm{~cm}$ to be considered a pass. $\mathrm{d} 1$ and $\mathrm{d} 2$ represent measurements in different directions 


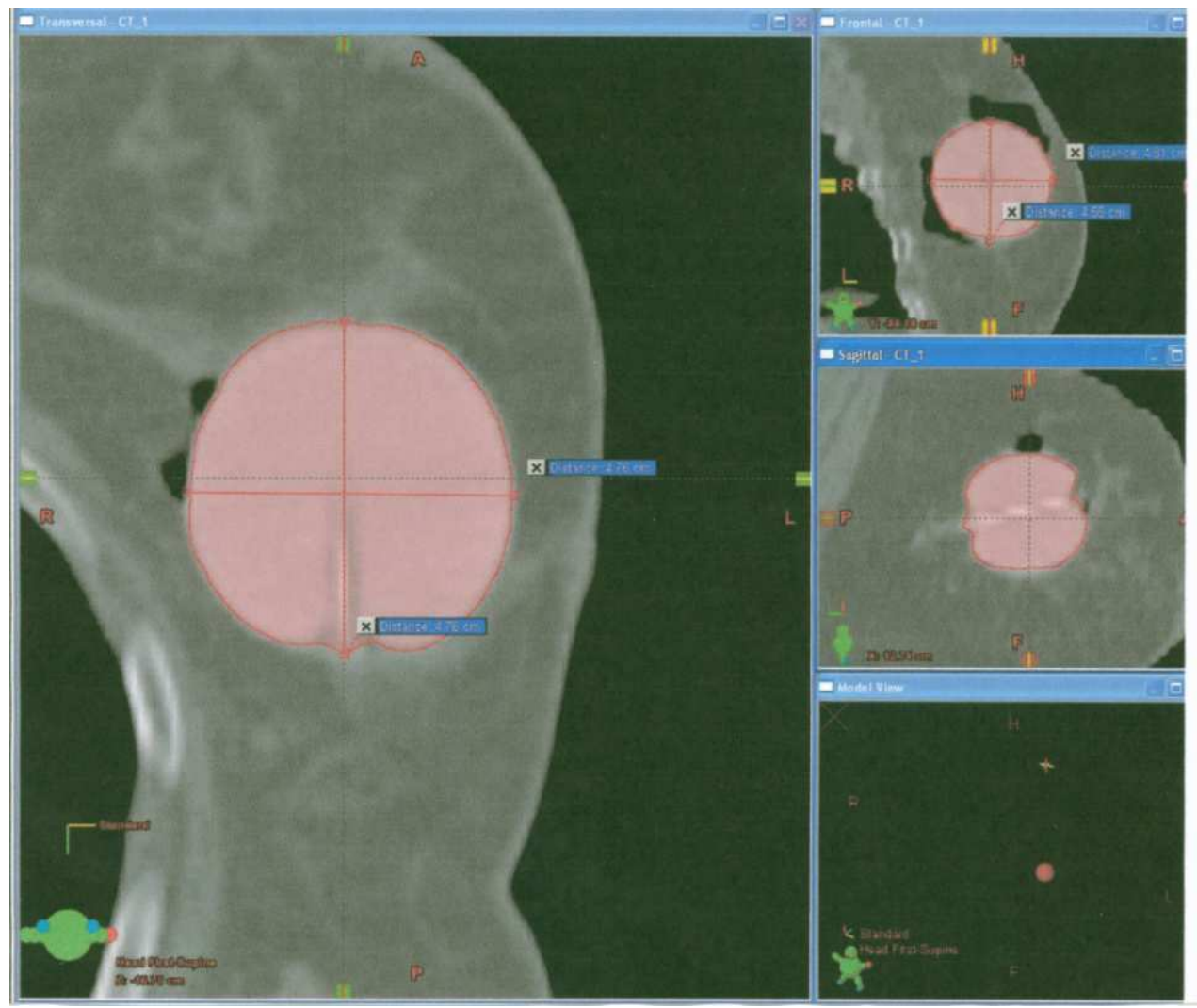

Fig. 7. This figure shows the measured diameters in three different orientations. Shown are the central CT slices with the longest diameters. In this figure, the diameters in all the CT views and directions are between $4.0 \mathrm{~cm}$ and $5.0 \mathrm{~cm}$ and therefore meets the requirements for the $4.0-5.0 \mathrm{~cm}$ diameter fluid inflated balloon.

\begin{tabular}{|l|c|c|c|c|}
\hline Orientation & $\mathrm{r} 1 \mathrm{~cm}$ & $\mathrm{r} 2 \mathrm{~cm}$ & $\mathrm{I} \mathrm{r} 1-\mathrm{r} 2 \mathrm{I} \mathrm{cm}$ & $\begin{array}{c}\text { I r1 }-\mathrm{r} 2 \mathrm{I} \leq 0.2 \mathrm{~cm} \\
\text { Pass/Fail }\end{array}$ \\
\hline Transverse & 2.23 & 2.40 & 0.17 & Pass \\
\hline Frontal & 2.29 & 2.46 & 0.17 & Pass \\
\hline Sagittal & 2.17 & 2.09 & 0.08 & Pass \\
\hline
\end{tabular}

Table 3. Evaluation of central lumen asymmetry. $r 1$ and $r 2$ represent opposing radii. The magnitude of the difference should not be more than $0.2 \mathrm{~cm}$ to be considered a pass. 


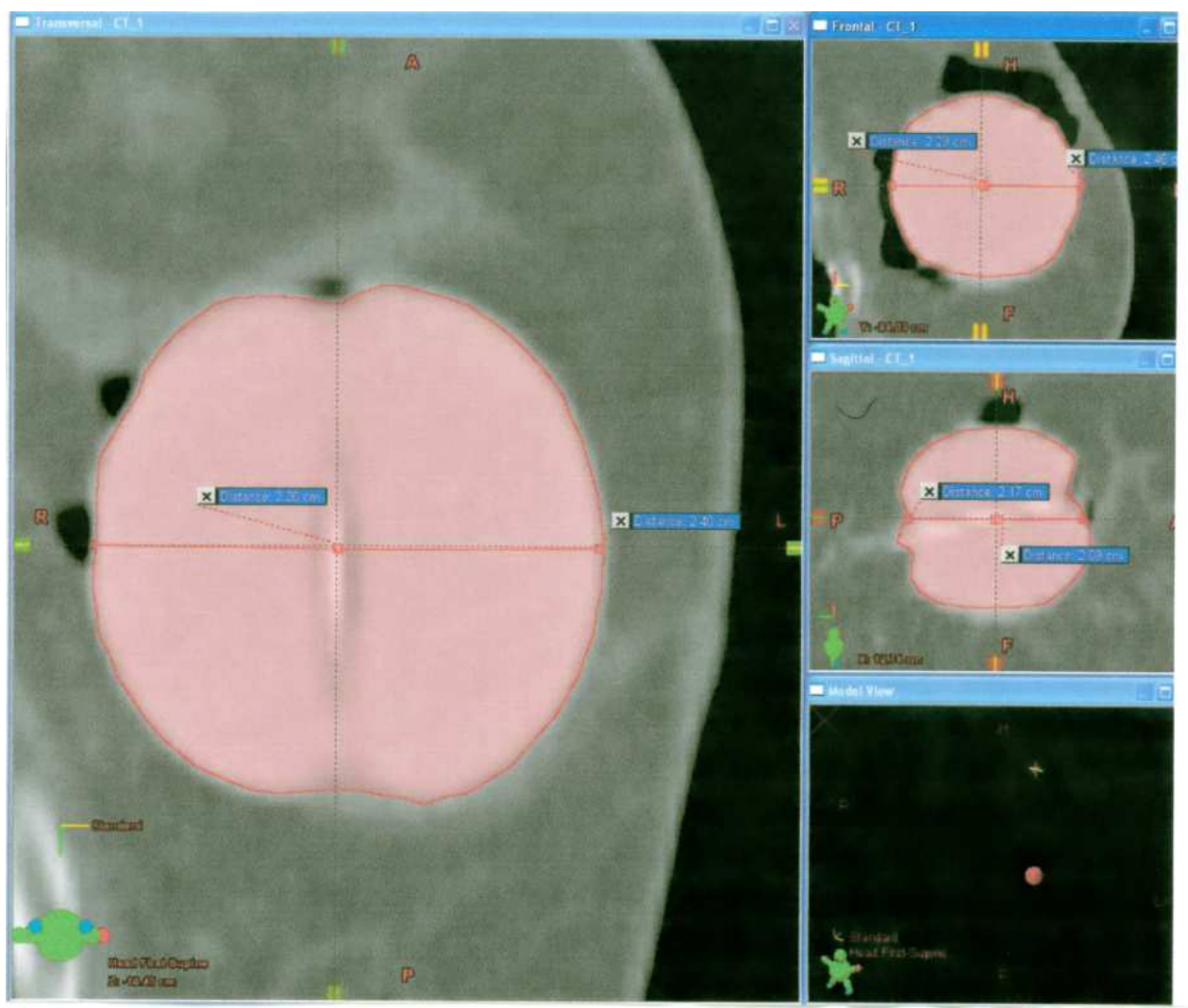

Fig. 8. This illustration is for the CT slices showing delineated balloon in three different views with the largest diameters. The measurements are made for the opposite radii. The maximum differences in the magnitude between the opposing radii in the transverse orientation is $1.7 \mathrm{~mm}$ which is less than $2.0 \mathrm{~mm}$ as required. The bottom right diagram exhibits a nearly spherical shape 3D model view of the balloon.

\begin{tabular}{|c|c|c|c|c|}
\hline Balloon $\left(\mathrm{cm}^{3}\right)$ & Air $\left(\mathrm{cm}^{3}\right)$ & PTV $\left(\mathrm{cm}^{3}\right)$ & Air/PTV (R) & $\begin{array}{c}\mathrm{R} \leq 0.1 \\
\text { Pass } / \text { Fail }\end{array}$ \\
\hline 56.9 & 6.17 & 164.47 & 0.038 & Pass \\
\hline
\end{tabular}

Table 4. Balloon, Air and PTV computed volumes. R should be less or equal to 0.1 to pass. 
From table 4, the 3D computed volume is $56.9 \mathrm{~cm}^{3}$ of a nearly spherical balloon. This gives a spherical radius of $2.386 \mathrm{~cm}$. From table 3, the average measured radius is $2.27 \mathrm{~cm}$. Consequently the measured radius compared to the computed radius differs only by 1.13 $\mathrm{mm}$ which is acceptable.

\subsection{Radiation dose prescription}

MammoSite RTS allows patients to receive their entire treatment in a week, rather than six or seven weeks. Patients have two treatments per day with a minimum 6 hour interfraction interval, over five treatment days (Radiation Therapy Oncology Group [RTOG], 2009). A total dose of $34 \mathrm{~Gy}$ is typically prescribed $1 \mathrm{~cm}$ from the surface of the balloon. Figure 5 demonstrates a CT scan which is taken each day of treatment in order to obtain the balloon radius, symmetry, and distance from the balloon's surface to the skin's surface.

\subsection{D Computerized treatment planning}

The anatomy based 3D treatment planning is performed using the CT images. These images can be fused with images obtained from other modalities such as MRI and PET to clearly define the treatment target. The PTV is obtained by first delineating the balloon using planning system software tools. The balloon surface is then expanded by $1 \mathrm{~cm}$ to obtain an expanded volume. Other regions of interest within this expanded volume such as air pockets, ribs, lungs, and muscle are then delineated (see figure 9). Skin is created by extracting the segmentation from the inner wall of the body by $0.5 \mathrm{~cm}$. These regions together with expanded volume lying outside the skin are then removed from the expanded volume to obtain the PTV (see Figure 10).

The air volume within the PTV and PTV volume are then computed. The ratio of the air volume to PTV volume should not be more than 0.1 . See table 4 for an example on the patient specific values.

The dummy sources in the CT images are also used to determine the single central dwell position of the radioactive source in the central lumen (see figure 11).

This position should be within $2 \mathrm{~mm}$ of the balloon center in order to achieve the precision of dose to the prescription point within 15\% (American Association of Physicists in Medicine [AAPM], 1995). Inverse treatment dose computation is then performed on the 3D images where prescription volume is used to optimize the source dwell position and duration. Figure 12 shows the dose-rate distribution and the dose volume histogram (DVH) that is helpful in evaluating the acceptability of the obtained treatment plan. The blue line represents 34 Gy prescription isodose line. The DVH (top right portion of figure 12) indicates that 34 Gy covers $99.6 \%$ of the PTV. It can be noticed from the frontal view that part of the skin, which is a normal organ at risk is receiving $39 \mathrm{~Gy}$, more than the prescribed dose because of its proximity to the PTV. The ribs and skin should not receive more than $145 \%$ of the prescribed dose. This is an undesirable, but important information that can only be obtained from the CT based 3D treatment plan evaluation.

\subsection{Daily quality control and treatment delivery}

Once an acceptable computerized treatment plan is obtained, a second independent point dose is calculated to validate the treatment planning computer generated radioactive source dwell durations (American Association of Physicists in Medicine [AAPM], 1995). The treatment parameters such as the treatment machine channel number, radioactive source 
dwell positions and dwell durations are then exported to the treatment delivery computer and then checked for deliverability before the patient is actually treated. In the example considered above, the measured radius of the balloon is $2.27 \mathrm{~cm}$. The HDR afterloader machine used has a combined MammoSite source train (radioactive source transfer tube) length of $130.0 \mathrm{~cm}$ with $0.5 \mathrm{~cm}$ reserved for the catheter tip. This is the combined length of the balloon catheter and source guide tube. Therefore the central lumen single dwell position is expected to be located at $127.73 \mathrm{~cm}$. However, for a dwell step size of $0.5 \mathrm{~cm}$, this location would be at $127.5 \mathrm{~cm}$. This value should be compared with the value generated by the afterloader remote control computer before activating the treatment delivery.

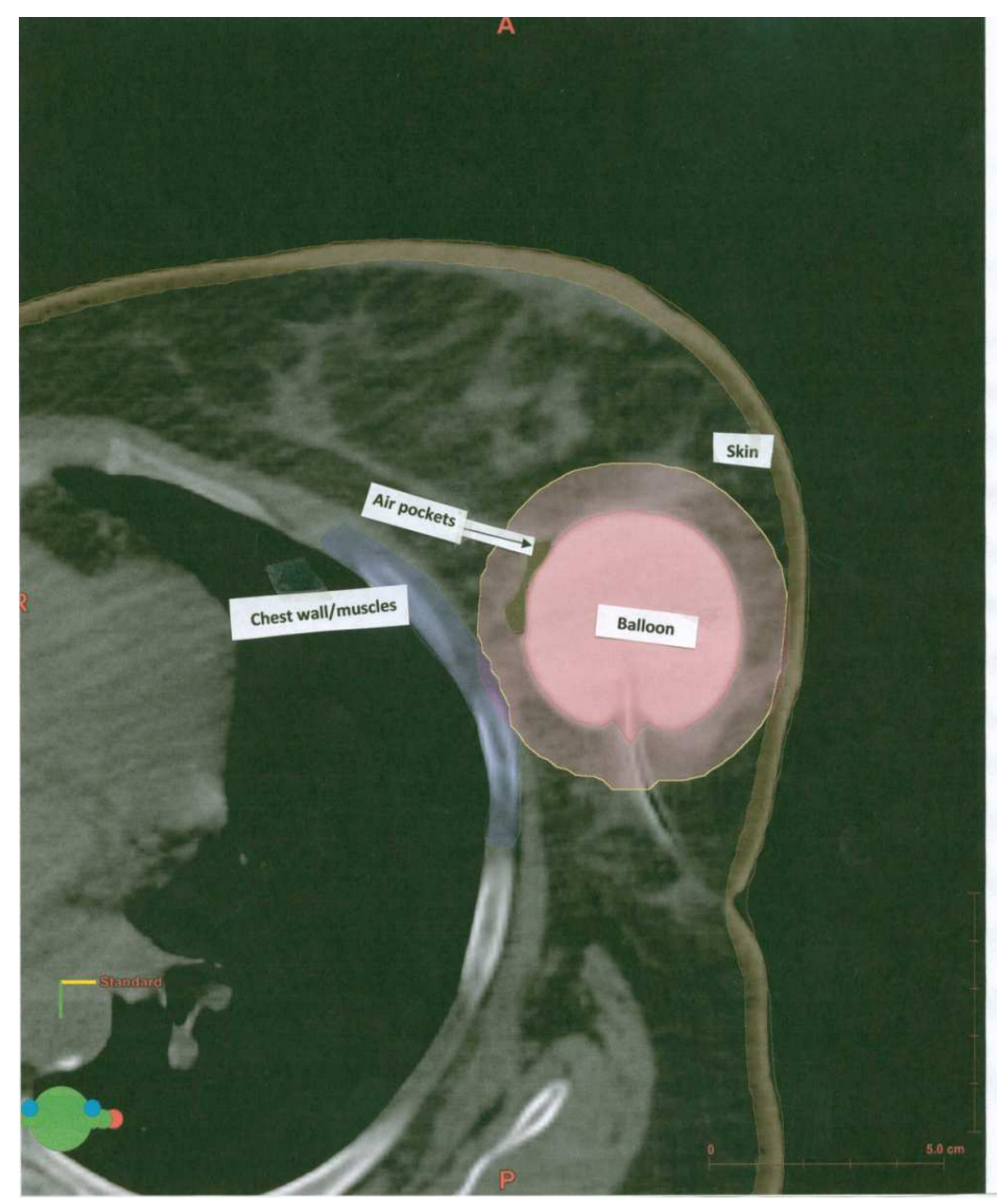

Fig. 9. The figure illustrates the delineated regions of interest. Blue- chest wall, red balloon, green- air gap, orange- skin, purple- expanded balloon. 


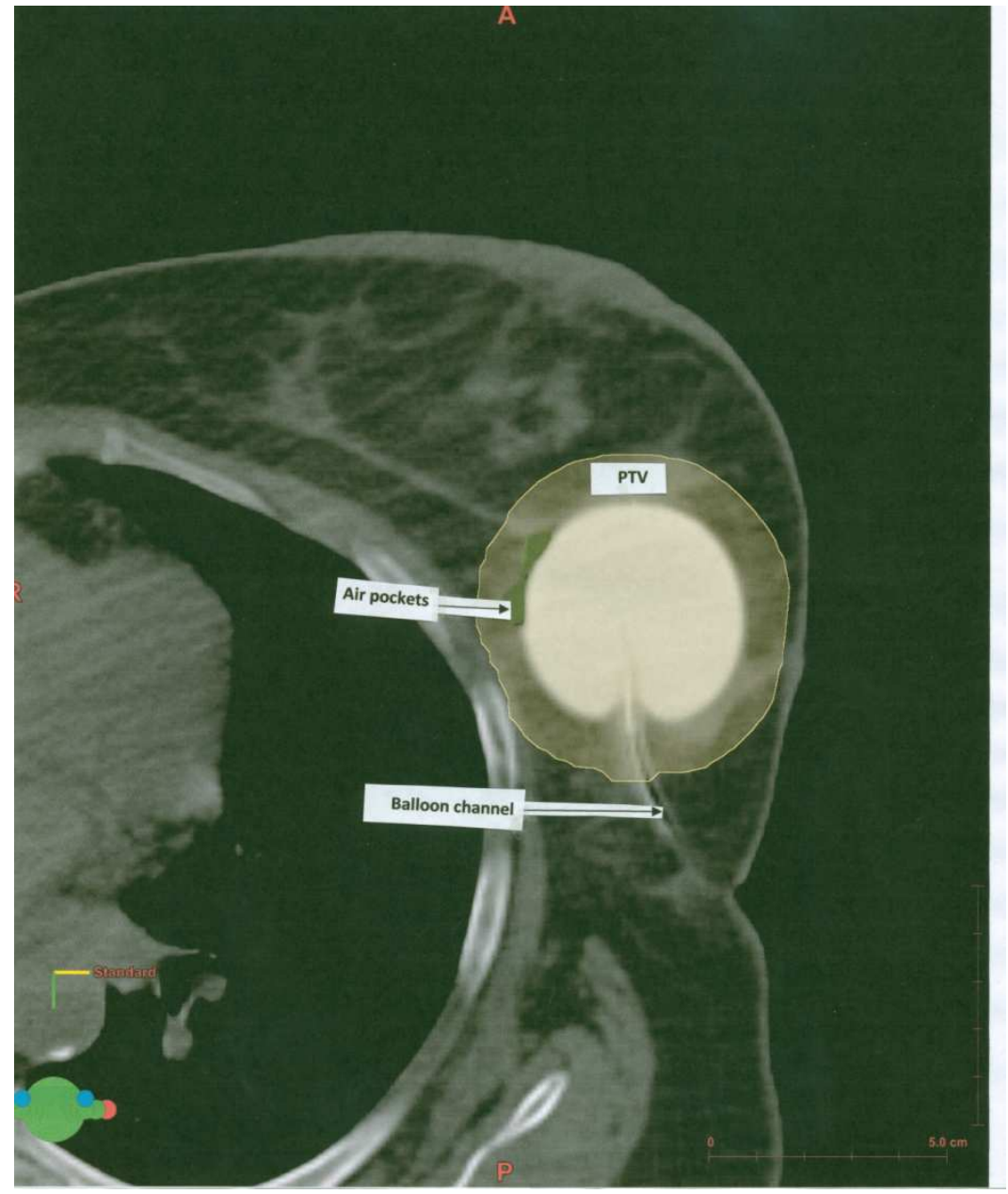

Fig. 10. This figure illustrates PTV with air pockets and a balloon catheter channel. The PTV is formed by removing all the regions of interest within the expanded balloon except the air pockets.

Before the first treatment of each day, CT imaging should be repeated to verify balloon position and its diameter. If balloon diameter changes by 10\% (MammoSite, 2010), balloon 
integrity must be examined, and a new computerized treatment plan may have to be generated.

The mechanically- controlled motion of the radioactive source from the remote afterloader to the balloon applicator is sensitive to the condition of the transfer tube and applicator. Daily imaging also aids to assure that there are no kinks or obstructions along the transfer tube and applicator situated on the breast to preempt any potential radiation safety issue.

The length and the orientation of the portion of the balloon applicator lying outside the skin surface should be checked to be constant before every treatment. Extra syringe should be available among the emergency kit to be used for draining and deflating the balloon in case of emergency or at the end of the final treatment delivery. The radioactive source transfer tube should not pass through the bed rail and the applicator connectors must be thoroughly cleaned after every usage following the manufacturers guidelines.

Figure 13 shows the treatment delivery system which is remotely controlled by the treatment delivery computer.

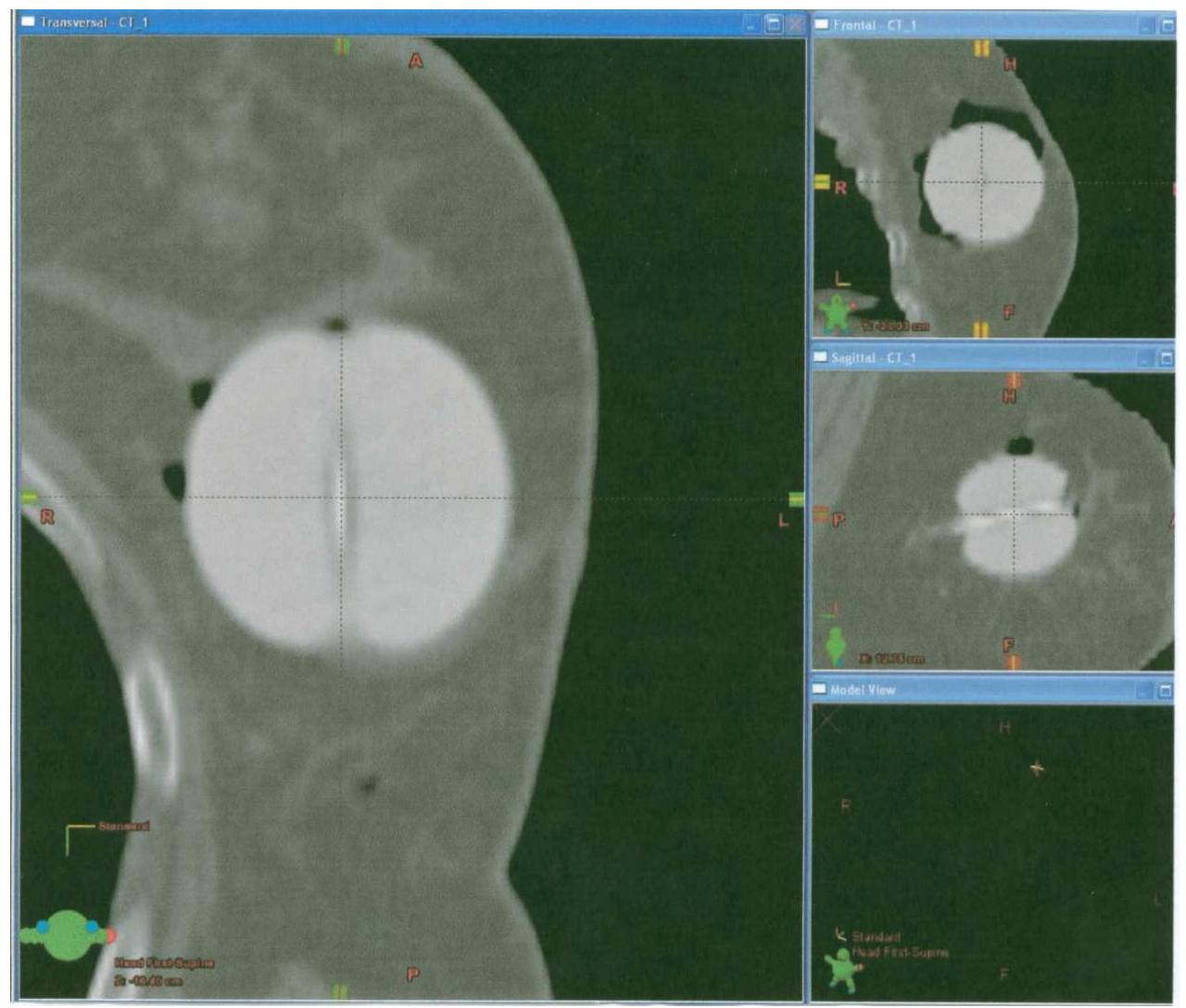

Fig. 11. The central radiographic marker (dummy source) is used to determine the central location of the single dwell source MammoSite RTS. 


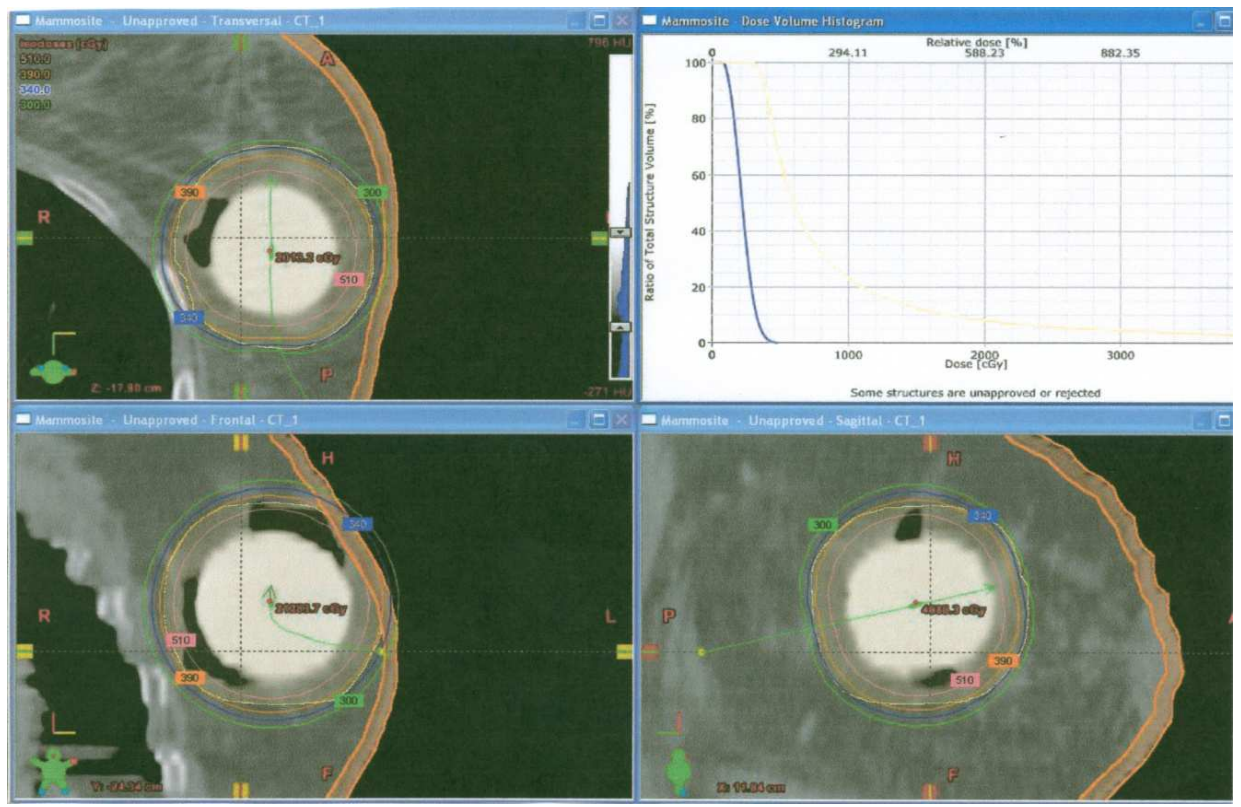

Fig. 12. 3D Treatment plan evaluation. Central bold green is the simulated radioactive source dwell position. Blue line is the $34 \mathrm{~Gy}$ prescribed isodose line

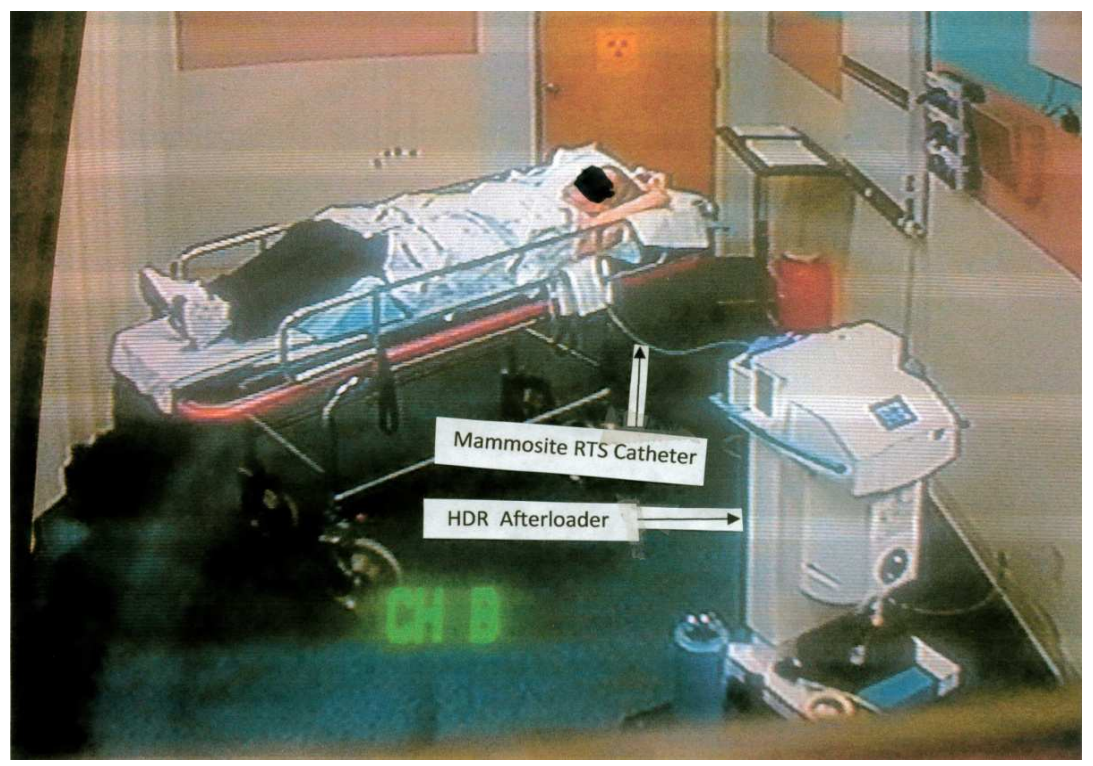

Fig. 13. Patient undergoing left breast Accelerated Partial Breast Irradiation using remotely computer controlled Varian Gammamed plus ix HDR afterloader via MammoSite RTS delivery system. 


\section{Conclusion}

CT aided brachytherapy planning provides advantages over plain radiograph-based brachytherapy planning, as individually customized treatment can be obtained with organs at risk spared from unnecessary radiation exposure. CT based 3D treatment planning software has improved brachytherapy treatment planning because dose in the target and critical organs can be predicted better. CT imaging is also superior when it comes to APBI pre-treatment appropriateness evaluation. However, despite the apparent dosimetric benefits, there is not yet clear clinical data demonstrating an improved therapeutic ratio. Since CT images provide tissue electron density information that can be incorporated into 3D planning systems, the brachytherapy dose calculation algorithms can now be developed further to correct for the tissue heterogeneities to provide more accurate treatments using the electron densities.

\section{References}

Almond, P. (1983). Remote afterloading, Chapter 8, In: Advances in Radiotherapy Treatment Planning, A.E. Wright, and A.L. Boyer (Eds.), pp. 601-619, American Institute of Physics, New York.

America Association of Physicists in Medicine (AAPM), (1995). Dosimetry of brachytherapy sources, AAPM task Group 43 Report, Med Phys. Vol.22, pp. 209-239.

American Cancer Society. (2003). Cancer facts and figures-2003, American Cancer Society, Atlanta.

Andersen, B.; Yang, H; Farrar, W.; Golden-Kreutz, D.; Emery, C.; Thornton, L.; Young, D. \& Carson, W. (2008). Psychological intervention improves survival for breast cancer patients: A randomized clinical trial, Cancer, Published Online: November 17, (DOI: 10.1002/cncr.23969); Print Issue Date: December 15, 2008

Besaleh, S.; Bezak, E. \& Bor,g M. (2009). Review of MammoSite brachytherapy: Advantages, disadvantages and clinical outcomes, Acta Oncol. Vol.48, No.40, pp. 487-494.

Byhart, R; , et al. (1978). Weekly localization films and detection of field placement errors, Int J Radiat Oncol Biol Phys Vol.4, pp. 881-887.

Calle, R.; Pilleron J.; Sclienger P. \& Vilcoq J. (1978). Conservative management of operable breast cancer: Ten years' experience at the Foundation Curie, Cancer, Vol.42, pp. 2045.

Calle, R.; Vilcoq, J.; Zafrani, B.; Vielh, P. \& Fourquest, A. (1978). Local control and survival of breast cancer treated with limited surgery followed by irradiation, Int J Radiat Biol Phys, Vol.12, pp. 873-878.

Delcos, L. (1980). Afterloading methods for interstitial .gamma-ray therapy. Chapter 1, In: Textbook of Radiotherapy, G.H. Fletcher (Ed.), pp. 84-92, Lea \& Febiger, Philadelphia.

Delcos, L. (1992). Afterloading interstitial irradiation techniques, Chapter 11, In: Levitt and Tapley's Technological Basis of Radiation Therapy, Practical Clinical Applications, S.L. Levitt, F.M. Khan, F.M., and R.A. Potish (Eds.), pp. 123-154, Lea \& Febiger. Philadelphia.

Edmundson, G. (1994). Volume optimization: An American viewpoint, In: Brachytherapy from irradium to optimization. R.F. Mould (Ed.), Veenendaal, Nucletron Intl BV.

Fisher, B.; Montague, E.; Redmond, C.; \& other NSABP investigators. (1977). Comparison of radical mastectomy with alternative treatments of primary breast cancer; a first 
report of results from a prospective randomized clinical trial, Cancer, Vol.39, pp. 2827.

Fisher, E.; Sass, R.; Fisher, B.; Gregorio, R.; Brown, R. \& Wickerham, L. (1986). Pathologic findings from the National Surgical Adjuvant Breast Project (protocol 6) II. Relation of local breast recurrence of multicentricity, Cancer, Vol.57, pp. 1717-1724.

Glasgow, G. (1995). Principals of remote afterloading devices. In: Brachytherapy Physics, J. Williamson, B. Thomadsen \& R. Nath (Eds), Medical Physics Publishing, Madison, Wisconsin.

Harris, J.; Botnick L.; Bloomer W., et al. (1981). Primary radiation therapy for early breast cancer: The experience of the Joint center for radiation Therapy, Int J Radiat Oncol Biol Phys. Vol.7, pp. 1549.

Henderson, I. \& Canellos, G. (1980). Cancer of breast: the past decade, N Engl J Med. Vol.30, pp. 17-30.

Henschkle, U.; Hilaris, B. \& Mahan, G. (1963). Afterloading in interstitial and intracavitary radiation therapy, $A J R$, Vol.90, pp. 386.

Hillaris, B. (Ed.). (1975). Afterloading, 20 Years of Experience 1955-1975, Proceedings of the II International Symposium on Radiation Therapy, American Institute of Physics, Memorial Sloan-Kettering Cancer Center, New York.

Holland, R.; Veling, S.; Mravunac, M. \& Hendricks, J. (1985). Histologic multifocality of Tis T1-2 breast carcinomas, Cancer, Vol.56, pp. 979.

Internationl Atomic Energy Agency (IAEA). (1967). Physical Aspects of Radioisotope Brachytherapy, technical Report Series No. 75, International Atomic Energy Agency, Vienna.

ICRU Report No. 50. (1983). Prescribing recording, and reporting photon beam therapy, T. Landberg et al (Eds), International Commission on Radiation Units and Measurements, Bethseda.

ICRU Report No. 62. (1999). Prescribing recording, and reporting photon beam therapy, (supplement to ICRU report 50), T. Landberg (Eds), International Commission on Radiation Units and Measurements, Bethseda.

Levene, M. (1977). Interstitial therapy of breast cancer, Int J Radiat Oncol Biol Phys. Vol.2, pp. 1157.

Lindfors K.; Boone J.; Nelson T.; Yang K.; Kwan A. \& Miller D. (2008). Dedicated Breast CT, Initial Clinical experience, Radiology,Vol.3, pp. 725-733.

MammoSite RTS (2010). Private communication.

Manning, M.; Zwicker, R.; Arthur, D., et al. (2001). Biologic treatment planning for highdose-rate brachytherapy, Int J Radiat Oncol Biol Phys. Vol.49, pp. 839-884.

McGee, J. \& McShan, D. (1988). Computerized Tomography for Ir 192 Iridium breast implants, In: Fortschritte in der interstitiellen und intrakavitaren Strahlentherapie, Karcher \& Hammer (Eds), pp. 105-109, W. Zuckschwerdt Verlag, Munchen, Bern, Wien.

Nath, R. (1993). New directions in radionuclide sources for brachytherapy, Semin. Radiat. Oncol., Vol.3, pp. 279-289.

Paine, C. (1972). Modem afterloading methods for interstitial radiotherapy, Clin. Radiol., Vol.23, pp. 263-272.

Pierquin, B.; Owen, R.; Maylin, C., et al. (1980). Radical radiation therapy of breast cancer. Int J Radiat Oncol Biol Phys. Vol.6. No.17. 
Prosnitz, L.; Goldenburg, I.; Packard, R., et al. (1977). Radiation therapy as initial treatment for early stage cancer of the breast without mastectomy, Cancer Vol.39, pp. 917.

Radiation Therapy Oncology Group (RTOG), NSABP B-39/RTOG 0413: A Randomized Phase III Study of Conventional Whole Breast Irradiation (WBI) versus Partial Breast Irradiation (PBI) for Women with Stage 0, I, or II Breast Cancer. Nov. 2, 2009, Available from: 208.251.169.72/members/protocols/0413/0413.pdf

Ricke, J.; Wust, P.; Stohlmann, A.; et al. (2004). CT-guided interstitial brachytherapy of liver malignancies alone or in combination with thermal ablation: phase I/II results of a novel technique, Int J Radiat Oncol Biol Phys. Vol.58, pp. 1496-1505.

Schottenfeld, D. et al. (1976). Ten-years results of treatment of primary operable breast carcinoma, Cancer, Vol.38. pp. 1005.

Souba, W.; Frank, M.; Jurkovich, G.; et al. (2007). ACs Surgery: principles and practice. New York: WebMD.

Syed, A . \& Feber, B. (1977). Technique of afterloading interstitial implant, Radiol. Clin., Vol.46, pp. 458-475.

Syed, A; Nisar, S. \& Feber, B. (1977). Techniques of afterloading interstitial implants. in Renaissance of Interstitial Brachytherapy, Proceedings of the 12th Annual San Francisco Cancer Symposium, California, pp. 119-135, Frontiers of Radiation Therapy Oncology, Vol.12, J.M. Vaeth,. (Ed.), S. Karger, Basel, 1978.

Trott, N. (Ed). (1988). Radionuclides in Brachytherapy, Radium and After, Br. J. Radiol., Suppl. 21, British Institute of Radiology, London.

Van Arsdale, E. \& Greenlaw R. (1971). Formalized immobilization and localization in radiation therapy, Radiology Vol. 99, pp. 697-698.

Zwicker, R.; Schmidt-Ullrich, R. \& Schiller, B. (1985). Planning of Ir-192 seed implants for boost irradiation of the breast, Int J Radiat Oncol Biol Phy.Vol. 11, pp. 2163. 


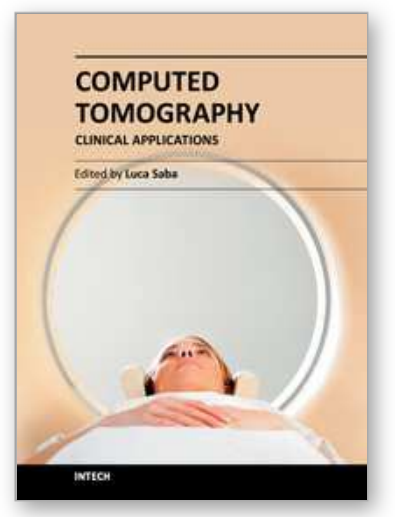

\author{
Computed Tomography - Clinical Applications \\ Edited by Dr. Luca Saba
}

ISBN 978-953-307-378-1

Hard cover, 342 pages

Publisher InTech

Published online 05, January, 2012

Published in print edition January, 2012

Computed Tomography (CT), and in particular multi-detector-row computed tomography (MDCT), is a powerful non-invasive imaging tool with a number of advantages over the others non- invasive imaging techniques. CT has evolved into an indispensable imaging method in clinical routine. It was the first method to non-invasively acquire images of the inside of the human body that were not biased by superimposition of distinct anatomical structures. The first generation of CT scanners developed in the 1970 s and numerous innovations have improved the utility and application field of the $\mathrm{CT}$, such as the introduction of helical systems that allowed the development of the "volumetric CT" concept. In this book we want to explore the applications of CT from medical imaging to other fields like physics, archeology and computer aided diagnosis. Recently interesting technical, anthropomorphic, forensic and archeological as well as paleontological applications of computed tomography have been developed. These applications further strengthen the method as a generic diagnostic tool for non- destructive material testing and three-dimensional visualization beyond its medical use.

\title{
How to reference
}

In order to correctly reference this scholarly work, feel free to copy and paste the following:

D. O. Odero (2012). CT Aided Postoperative Breast Conservation Brachytherapy Irradiation, Computed Tomography - Clinical Applications, Dr. Luca Saba (Ed.), ISBN: 978-953-307-378-1, InTech, Available from: http://www.intechopen.com/books/computed-tomography-clinical-applications/ct-aided-postoperative-breastconservation-brachytherapy-irradiation

\section{INTECH}

open science | open minds

\section{InTech Europe}

University Campus STeP Ri

Slavka Krautzeka 83/A

51000 Rijeka, Croatia

Phone: +385 (51) 770447

Fax: +385 (51) 686166

www.intechopen.com

\section{InTech China}

Unit 405, Office Block, Hotel Equatorial Shanghai

No.65, Yan An Road (West), Shanghai, 200040, China

中国上海市延安西路65号上海国际贵都大饭店办公楼 405 单元

Phone: +86-21-62489820

Fax: $+86-21-62489821$ 
(C) 2012 The Author(s). Licensee IntechOpen. This is an open access article distributed under the terms of the Creative Commons Attribution 3.0 License, which permits unrestricted use, distribution, and reproduction in any medium, provided the original work is properly cited. 